\title{
Lebendnierenspende: geringes Kurz-, kein Langzeitrisiko
}

Die bislang umfangreichste und sorgfältigste Studie beseitigt letzte Zweifel: Die Lebenserwartung wird durch eine Nierenspende nicht beeinträchtigt.

- An das nationale US-Register müssen alle Lebendnierenspenden gemeldet werden. Zwischen 1994 und 2009 erfolgten 80347 Eintragungen. Es gab 25 Todesfälle bei den Spendern innerhalb von 90 Tagen nach Nephrektomie, d. h. 3,1 Todesfälle pro 10000 Spender. Damit liegt die perioperative Mortalität im Vergleich mit anderen Eingriffen sehr niedrig: Sie beträgt für die laparoskopische Cholezystektomie 18, für Nephrektomien aus anderer Indikation 260 pro 10000 Patienten.

Die Beobachtungsdauer nach der Nierenspende erreichte im Mittel 6,3
Jahre. Die Überlebensdauer der Spender wurde mit einer besonders gesunden Probandengruppe aus der NHANES-III-Studie verglichen. Dabei war die Mortalität der Nierenspender nicht erhöht.

\section{Kommentar}

Der Nutzen für die Empfänger darf nicht durch ein unangemessenes Kurz- und Langzeitrisiko für die Nierenspender erkauft werden. Die Nephrektomie beinhaltet ein unvermeidliches Risiko, doch ist dieses im Vergleich zu anderen Eingriffen bemerkenswert gering.

H. Holzgreve -

- D. L. Segev et al.

Perioperative mortality and long-term survival following live kidney donation. JAMA 303 (2010) 959-966

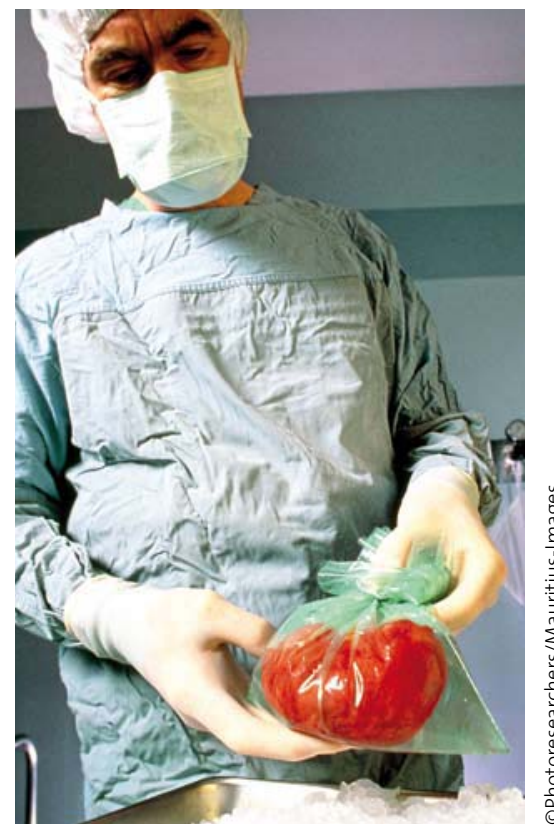

Nierenspender leben nicht gefährlich. 